\title{
devir-professor brasileiro em tempos de pandemia
}

\author{
meirilene dos santos araújo barbosa \\ universidade federal do ceará, fortaleza, ceará, brasil \\ orcid id: https:/ / orcid.org/0000-0003-0803-0557 \\ laís helena garcia \\ universidade federal do ceará, fortaleza, ceará, brasil \\ orcid id: https:/ / orcid.org/0000-0002-8787-2535 \\ ana maria monte coelho frota \\ universidade federal do ceará, fortaleza, ceará, brasil \\ orcid id: https:/ / orcid.org/0000-0003-4890-5821
}

resumo

Para tentar compreender algumas nuances do devir-professor brasileiro em tempos de pandemia, foi realizado um estudo de natureza exploratória, de cunho bibliográfico, no qual foram considerados os desafios, limites e as possibilidades do trabalho docente. As discussões teóricas sobre o tema envolveram um diálogo que considerou a Pedagogia, a Filosofia da educação e a experiência dos acontecimentos políticos e sociais no período de pandemia da Covid-19 a partir das contribuições de Caponi (2020), Kohan (2007, 2008, 2010, 2011, 2017), Larrosa (2018), Neuscharank (2020), Vaz (2012), Arroyo (2012) e Abramowicz (2017). As discussões nos levam a crer que: o contexto mundial de pandemia provocado pela Covid-19 afetou profundamente a forma de viver, trabalhar e se relacionar com o outro, especialmente devido ao isolamento social, solicitando do professor brasileiro abertura para mudanças e uso de novas tecnologias, com a clara defesa de que estas não substituem as interações presenciais; as dificuldades provocadas no processo pelo fortalecimento da lógica neoliberal propiciou o debate sobre que escola temos e que escola queremos, que professores somos e que professor queremos ser; o olhar para as possibilidades de "devir-criança" enquanto desejo e abertura para o novo pode ser um convite a pensar em um "devir-professor" que se deixe atravessar por outra lógica, por outra temporalidade mais sensível e mais estética; o encontro com outros, com a arte, com a infância, com o devir pode ajudar a pensar, a resistir, a lutar.

palavras-chave: devir; professor; pandemia.

\section{becoming brazilian teacher in pandemic times}

\section{abstract}

This paper seeks to explore the processes involved in becoming a teacher in this particular historical moment of global pandemic in Brazil. What are the challenges, limitations, possibilities and opportunities that the pandemic presents to the process of teaching work and teacher formation? A review of the literature that included contributions from Caponi (2020), Kohan (2007, 2008, 2010, 2011, 2017), Larrosa (2018), Neuscharank (2020), Vaz (2012), Arroyo (2012) and Abramowicz (2017) suggests a dialogue between pedagogic theory, philosophy of education and the contemporary experience of political and social events in the pandemic period The discussions reviewed explore the profound extent to which Covid-19 has affected our way of living, working and relating to others, and the psychological effects of social isolation. The situation demands from the Brazilian teacher an attitude of openness to change, specifically in the use of new technologies, and the extent to which they are or are not able to replace face-to-face interactions. The situation also challenges us to reconstruct, beyond the logic of neoliberalism, our notions of the type of 
devir-professor brasileiro em tempos de pandemia

school we have and type of school we want, the type of teachers we are and the type of teacher we want to be. We conclude that this process of thinking school again depends, if it is to escape neoliberal logic, on the capacity of understanding the vocation of the teacher to be one of "becoming-child" in the sense of experiencing an openness to and a desire for the new. As such, the "becoming-teacher" is one who allows herself to be addressed by another logic, another more sensitive and more aesthetic temporality, and who finds, in encounter with others, with art, with childhood, with becoming itself, the capacity to think, to resist, to fight for the realization of that logic.

keywords: becoming; teacher; pandemic.

\section{devenir maestro/a brasileño/a en tiempos de pandemia}

\section{resumen}

Para intentar comprender algunas gradaciones del devenir-maestro brasileño en los tiempos de pandemia, ha sido realizado un estudio de naturaleza exploratoria, de carácter bibliográfico, en el cual han sido considerados los desafíos, límites y posibilidades del trabajo docente. Las discusiones teóricas sobre el tema envolvieron un diálogo que ha considerado la Pedagogía, la Filosofía de la Educación y la experiencia de los acontecimientos políticos y sociales en el periodo de pandemia de Covid-19, desde las contribuciones de Caponi (2020), Kohan (2007, 2008, 2010, 2011, 2017), Larrosa (2018), Neuscharank (2020), Vaz (2012), Arroyo (2012) y Abramowicz (2017). Las discusiones nos llevan a creer que: el contexto mundial de pandemia provocado por la Covid-19 ha afectado profundamente la forma de vivir, trabajar y de relacionarse con el otro, especialmente a causa del aislamiento social, pues solicita del maestro brasileño aceptar cambios y el uso de nuevas tecnologías, con la clara defensa de que estas no sustituyen las interacciones presenciales; las dificultades provocadas en el proceso por el fortalecimiento de la lógica neoliberal han propiciado el debate sobre qué escuela tendremos y qué escuela deseamos, qué profesores somos y qué profesor deseamos ser; el mirar para las posibilidades del "devenir-niño", mientras el deseo por la abertura para lo nuevo puede ser una invitación a pensar en un "devenir-maestro" que permita atravesar por otra lógica, por otra temporalidad más sensible y más estética; el encuentro con los otros, con el arte, con la infancia, con el devenir puede ayudar a pensar, a resistir, a luchar.

palabras clave: devenir; maestro; pandemia. 
devir-professor brasileiro em tempos de pandemia

\section{sobre o contexto brasileiro durante a pandemia}

Estamos em fevereiro de 2021 e, nesse momento, temos em nosso país 10.139.148 casos confirmados de Covid-19 e 245.977 mortos pela doença, conforme os dados do Ministério da Saúde (Vidale, 2021, p. 1). Os casos, que se iniciaram em Wuhan, na China, em dezembro de 2019, foram se espalhando aos poucos pelo mundo, tendo o primeiro caso confirmado no Brasil em fevereiro de 2020 (Brasil, 2020, p. 1). A partir de então, o número de pessoas contaminadas pela doença foi se multiplicando e tomando em todo o mundo, proporções de surto. Em março de 2020, a Organização Mundial da Saúde (OMS) definiu a situação como pandemia e esse contexto tornou-se avassalador em vários sentidos. Pelo fato de ser uma doença viral contagiosa, nova e desconhecida para a comunidade científica, as medidas de prevenção orientadas foram, principalmente, o uso de máscaras, a higienização constante das mãos e o isolamento social.

No caso do Brasil, houve sério agravante do período pandêmico: o negacionismo assumido pelo governo federal, do qual se esperavam as devidas medidas de cuidado e preservação da vida. Enquanto isso, "eles continuaram negando e obstaculizando as medidas impostas por alguns governadores para conter a epidemia" (Caponi, 2020, p. 209). Essa situação demonstrou deliberadamente a posição do governo federal e de seus seguidores de assumir a razão neoliberal.

Para entender como se naturalizou essa lógica que defende a manutenção do mercado, mesmo que isso possa custar a vida de nossos seres mais queridos, é preciso lembrar que o neoliberalismo não só produz serviços e bens de consumo, ele também produz modos de ser sujeito. Um sujeito que reivindica por sobre todas as coisas sua liberdade de correr e assumir seus riscos; um sujeito empreendedor que acredita ser responsável absoluto por seus êxitos e fracassos, sem nada dever ou pedir ao estado (Caponi, 2020, p. 217).

Frigotto (1996, p. 9) afirma que a ideia-força de efeito letal da avassaladora ideologia neoliberal "é a de fazer crer que não há outra saída para a humanidade senão curvar-se à férrea lógica do mercado [...]", desse modo, ao assumir o negacionismo, o governo federal, em vez de planejar o enfrentamento da situação 
devir-professor brasileiro em tempos de pandemia

com medidas já adotadas com efetividade por outros países, preocupou-se, ao contrário, em minimizar a gravidade da pandemia e eximir as responsabilidades do estado com as políticas sociais.

Shiroma, Moraes e Evangelista (2011, p. 9) asseveram que “compreender o sentido de uma política pública reclamaria transcender sua esfera específica e entender o significado do projeto social do Estado como um todo e as contradições gerais do momento histórico em questão". O que pensar ou dizer, portanto, quando, em plena reunião ministerial, se propõe aproveitar a oportunidade de mobilização da imprensa e da sociedade ao tema da Covid-19 para "ir passando a boiada"1? A estratégia adotada pelo governo foi usar diversos meios tecnológicos de comunicação para expandir o discurso de que, caso a economia parasse, mais pessoas morreriam de fome do que acometidas pelo vírus.

Em artigo sobre a Covid-19 no Brasil, Sandra Caponi (2020, p. 210) registra que:

No dia 14 de maio de 2020 o presidente Bolsonaro declarou que estamos em guerra. Mas ele não se referia à questionável metáfora utilizada por outros presidentes quando falam de guerra contra a pandemia. Pelo contrário, o presidente Bolsonaro preferiu declarar guerra aos governadores e prefeitos que, em diferentes estados do Brasil, defendem a implantação de políticas de isolamento social. E para isso, pediu ajuda aos empresários afirmando que eles devem obstaculizar as medidas de quarentena. De fato, essa guerra enunciada e declarada em 14 de maio já estava em curso desde o momento em que começaram a implementar-se as primeiras medidas de controle à epidemia, agravando-se depois da demissão do ministro Henrique Mandetta.

Com o crescente número de vítimas e as milhares de vidas ceifadas, apesar de muitas pessoas negarem a gravidade da pandemia, alguns governadores decretaram medidas de isolamento e, dessa forma, houve a paralisação temporária de diversos serviços, incluindo as aulas presenciais nas instituições escolares do país. Com isso, houve uma necessidade de reorganização em vários setores, o que os levou a funcionar de forma remota ou à distância, especialmente com o uso de tecnologias, como computador, celular, internet.

\footnotetext{
1 "Ir passando a boiada" foi a expressão utilizada pelo Ministro do Meio Ambiente, Ricardo Salles, em reunião ministerial do dia 22 de abril de 2020, referindo-se à oportunidade de aproveitar o foco da mídia na pandemia da Covid-19 para aprovar, sem resistência da sociedade civil a revogação de resoluções de proteção ao meio ambiente (Gonçalves, 2020).
} 
Sobretudo no período mais crítico, o contexto da pandemia nos apresentou um cenário desconhecido, no qual as rotinas de quase todas as pessoas tiveram que ser alteradas. A opção aparentemente mais prudente que tínhamos era de ficarmos em casa, já que, por diversas vezes, assistimos, pela televisão, à sobrecarga dos hospitais e à falta de respiradores e insumos; até mesmo para preservar a vida das equipes de saúde que estavam à frente do atendimento aos infectados.

Esse fato trouxe à tona as condições reais da maior parte das famílias brasileiras: ficar em casa, mas em qual situação de moradia, alimentação, higiene? Muitas crianças e jovens longe da escola ficaram ainda mais vulneráveis às situações geradas principalmente pela desigualdade econômica e social. A partir de então, iniciou-se também uma preocupação com o esvaziamento das escolas. Como minimizar os danos do distanciamento? Como continuar o atendimento a crianças e adolescentes apesar das dificuldades?

Nossa atuação como professores também precisou ser repensada. O que poderia ser feito para tentar garantir a continuação do processo de formação de crianças, considerando suas múltiplas linguagens, sensibilidade, saberes e especificidades, nesse momento tão peculiar? Como oferecer uma formação comprometida com as outras pessoas, com a luta pelo direito ao respeito à diversidade, com a preservação do mundo onde vivemos e com as demais formas de vida, em um contexto de tanta desigualdade, mais agravada ainda pela pandemia da Covid-19?

Esse cenário exigiu dos professores conhecimento e aprendizagens sobre o uso de novas tecnologias, novas formas de ensinar, novas maneiras de interagir com os (as) estudantes, algo para além da formação inicial ou continuada que até então recebiam. Uma situação perigosa, pois, enquanto buscamos uma forma de continuidade do atendimento a crianças e jovens utilizando esses recursos, também podemos estar, mesmo que ingenuamente, abrindo precedentes que possibilitem a validação dos projetos de mercantilização das escolas e privatização da educação o que, de fato, não queremos, pois defendemos a escola pública, gratuita para todos, em condições dignas e adequadas, "uma escola em que vale a pena continuar caminhando" (Morales, 2018, p. 165). 
devir-professor brasileiro em tempos de pandemia

Em publicação para a 20a Semana Nacional em Defesa e Promoção da Educação Pública, a Conferência Nacional dos Trabalhadores em Educação (CNTE) alerta sobre os projetos de privatização e mercantilização da educação pública:

A privatização da educação pública se dá a partir de um processo lento e gradual, quase de forma despercebida para a maioria. E também através de muitas formas que, na maioria das vezes, são antecedidas por lógicas mercantis que transformam a educação de um direito social para um bem que pode e deve ser comercializado (CNTE, 2019, p. 2).

Também Larrosa (2018, p. 205), ao tratar das maneiras de dar aula, apresenta um fragmento do livro Nueva ilustracíon radical, de Marina Garcés (2017), para alertar sobre as tentativas de "desinstitucionalizar a educação" e de converter a sala de aula em uma máquina ou um ambiente:

A escola do futuro já começou a ser construída, e não a estão pensando os estados nem as comunidades, mas sim as grandes empresas de comunicação e os bancos. Não tem paredes, nem valas, mas plataformas on-line e professores 24 horas por dia. Não lhe fará falta ser excludente porque será individualizadora, de talentos e de percursos vitais e de aprendizagem. Praticará a universalidade sem igualdade: uma ideia em que temos que começar a pensar porque será, se já não é, a condição educativa de nosso tempo (Garcés, 2017, p. 61 apud Larrosa, 2018, p. 205).

Diante desse contexto difícil, observando que as demandas da pandemia e do neoliberalismo cada vez mais nos sufocam, precisamos nos perguntar sobre que escola estamos legitimando; perguntar-nos, como sugere Larrosa (2018, p. 210): “[...] o que é (e o que não é) ensinar? o que é (e o que não é) aprender? o que é (e o que não é) formação? o que é (e o que não é) educação?" Para que, enquanto professores, possamos buscar rotas de fuga que nos ajudem a pensar, a agir, a lutar. Talvez juntando forças, talvez na perspectiva da construção de um devir-professor.

\section{sobre limites e possibilidades}

O contexto da pandemia que ainda vivemos, com todas as perdas e todas as dores que tem provocado, vem nos forçando ao contato com a incerteza, com o inesperado. Não sabemos ao certo quando voltaremos a nos encontrar presencialmente, quando seremos imunizados, quando poderemos voltar para as escolas. Para alguns profissionais da educação, trabalhar em casa, de forma remota, significou algo extremamente desafiador, e até danoso, em muitas situações. 
Exigindo-se do professor um corpo disciplinado, seguindo fielmente um "tempo mecânico", um "tempo de mercado", com "hora certa" para todas as atividades.

No entanto, se refletirmos sobre as práticas escolares, no que se refere a esse aspecto, podemos perceber que também a escola tem desenvolvido, em crianças e jovens, principalmente as competências consideradas necessárias para as demandas de mercado, buscando adaptar os sujeitos à sociedade. Muitas coisas que até então feitas na escola eram totalmente objetivadas. Até mesmo as brincadeiras são entendidas, por vezes, como uma "ferramenta pedagogizante", usada para ensinar algo e possibilitada principalmente quando havia uma finalidade específica, como se não fosse uma forma de as crianças interagirem com o mundo.

Outras estratégias e políticas a serviço do neoliberalismo são denunciadas por Freitas (2020, p. 1):

[...] as políticas de accountability (responsabilização) atuam tanto no plano material (privatização e destruição da escola pública) como no plano da formação cultural dos estudantes, professores e gestores, neste caso, pela difusão de uma geocultura meritocrática que "ensina" principalmente a juventude a inserir-se na concorrência e a justificar seus avanços exclusivamente pelo mérito individual.

Um sentimento meritocrático vai tomando conta das crianças desde o início de sua formação e começa a ser o parâmetro de julgamento e justificação que diferencia quem tem direito a ter direito (pelo mérito) e quem não tem. A própria estrutura de classes sociais começa a ser justificada pela posse do mérito, transmutando as complexas desigualdades sociais, reduzidas, agora, a simples desigualdades de mérito. E este sentimento construído ao longo de todo o processo educativo, contribui posteriormente para explicar também quem está incluído e quem não está incluído no acesso aos direitos sociais e políticos.

Podemos afirmar que a escola como a conhecemos atende às políticas neoliberais e influencia diretamente a formação das crianças e a construção de seus valores. Segundo Moriyón (2010), no contexto atual, as crianças têm a garantia de seus direitos fundamentais negados, tais como o de pensar e decidir, inclusive sobre suas próprias vidas. Para o autor, seria necessário "conceder às crianças um protagonismo muito maior na gestão daqueles espaços e tempos nos quais estão diretamente implicados" (Moriyón, 2010, p. 150).

Nesse contexto, o professor, por vezes, repete as normatizações colonizadas da escola. Cabe-nos, porém, compreender que: 
devir-professor brasileiro em tempos de pandemia

Uma escola digna, uma educação digna ou um professor digno é uma escola, uma educação e um professor que merecem o seu nome, isto é, uma escola, uma educação ou um professor 'de verdade', que sejam 'realmente' escola, 'realmente' educação ou 'realmente' professor, e não esses simulacros indignos a que somos condenados pelas tabelas e rankings de qualidade (Larrosa, 2018, p. 44 , grifos do autor).

A escola já enfrentava várias problemáticas, mas, agora, corre risco ainda pior. Enquanto muitas pessoas percebem a pandemia como uma oportunidade para pensar e efetivar políticas de investimento nos setores sociais mais vulneráveis, dentre eles a educação; outras pessoas adotam, como no caso do Brasil, “[...] uma estratégia negacionista que continua cumprindo fielmente com as exigências do neoliberalismo, como se absolutamente nada devesse mudar com a pandemia" (Caponi, 2020, p. 218).

Dessa maneira, com o corte e congelamento de verbas orçamentárias a serem investidas na escola pública, passam a estrangular seu financiamento, pois, com escolas sucateadas, torna-se mais fácil convencer todos da necessidade de passá-las à iniciativa privada, ou, ainda, de militarizá-las em nome da sua eficiência e da ordem, além de elegerem os/as educadores/as como inimigos/as do país (CNTE, 2019).

Poderiam todos esses acontecimentos nos ajudar a buscar as necessárias mudanças? Poderiam nos provocar e mover na busca de mais dignidade para a escola, para a educação, para estudantes e professores?

Kohan (2010, p. 11) nos inquieta quando questiona: "pode ser a escola espaço de outra política da infância sensível à voz das crianças?" Sobre a questão da organização do tempo na escola, Kohan (2017) nos alerta que, etimologicamente, a palavra escola deriva do grego skholé, com o senso de lazer, tempo livre. “Assim a escola nasce, entre os gregos como um espaço com o tempo liberado, ou seja, para poder formalmente perder tempo, para libertar o tempo de seus habitantes de outra coisa que não seja o próprio estudo e exercício, na busca da formação de si" (Kohan, 2017, p. 11). No entanto, como afirma Neuscharank (2020, p. 3),

As escolas e as políticas e normas públicas educacionais tomaram essa representação linear do khrónos para organizar o trabalho pedagógico: o currículo foi fragmentado em anos e em uma sequência sucessiva, onde os estudantes precisam passar pelo 
primeiro ano para avançar para o segundo, precisam ver determinados "conteúdos" para aprofundar no ano seguinte.

Em contrapartida, há uma defesa de que a educação precisa ser pensada e discutida em seus princípios e objetivos em nosso contexto. Pensar sobre qual o sentido da educação poderia nos ajudar a superar essa busca de atender demandas de mercado e caminhar em outra direção? Talvez em uma direção mais humana, mais cuidadosa e mais democrática, por exemplo, no sentido que é apontado por Trindade (2018) a partir do conceito "vocação ontológica de ser mais", de Freire:

Este termo é utilizado por Freire (2010) como vocação ontológica do ser humano, ou seja, significa para o professor e aluno, a necessidade de potencializar a amorosidade enquanto prática educacional. Amorosidade significa a prática do amor na relação professor e aluno e o comprometimento com a essência de cada um. Essa prática na Educação levaria à consciência de ambos, como pessoas mais amáveis e menos opressoras (Trindade, 2018, p. 2).

Nesse sentido, Kohan (2017, p. 13) nos convida a olhar para a infância e nos propõe a inversão da lógica temporal cronológica mercadológica:

É preciso, então, devolver à escola o tempo infantil que lhe foi roubado [...]. Trata-se de uma simples inversão: em vez de submeter a Educação Infantil às exigências dos níveis ulteriores de escolaridade, padronizando e sequenciando modelos e conteúdos, poderíamos na escola, brincar um pouco mais, perder um pouco mais de tempo, fazer, fazer as coisas por elas próprias e não pelo que se obtém delas, estar um pouco mais presentes no presente...

No entanto, ao nos depararmos com toda a organização cronológica do mercado que colonizou a educação, deparamo-nos também com alguns professores e algumas professoras com extrema dificuldade de abandonar as certezas de quem ele (a) se considera ser, de uma identidade considerada formada por eles (as), que pode provocar o medo de mudar, de reconhecer as diferenças.

Outros aspectos que podemos citar como limites passam pelas desigualdades que se explicitam com a necessidade do uso das tecnologias. No contexto da pandemia, muitos professores precisaram garantir um acesso à internet, adquirir celulares e computadores com capacidade que possibilitasse uma boa comunicação; tiveram que aprender a usar programas e plataformas que até então desconheciam. Poucos tiveram recursos disponibilizados pelos órgãos públicos para atender essas demandas. Além disso, precisaram, ainda, conciliar trabalho, serviços domésticos e, 
devir-professor brasileiro em tempos de pandemia

muitas vezes, cuidados e acompanhamento dos filhos. Enfim, muitas mudanças, além da invasão de sua privacidade.

Dessa forma, mesmo reconhecendo os prejuízos das aulas virtuais, a inconveniência da exposição de seus ambientes particulares e de seus familiares; mesmo percebendo o aumento nos gastos financeiros com energia, internet $\mathrm{e}$ desgaste de seus equipamentos, a dificuldade do uso das tecnologias e de ferramentas nunca antes utilizadas; muitos professores buscaram meios de estar de alguma forma próximos dos estudantes e moveram-se a procurar algumas possibilidades nessa empreitada.

No entanto, é preciso compreender que se tornar professor (a) é um processo que envolve idas e vindas, exige flexibilidade, abertura para as novas possibilidades de fazer, de pensar, de outros olhares ao longo da formação; coloca os (as) profissionais em um movimento contínuo e não estático, mas que requer principalmente a reflexão sobre o que estamos fazendo, para quem e qual o sentido de nossas ações.

Em decorrência da necessidade de um enfrentamento mais efetivo às novas ondas de contaminação da Covid-19, iniciou-se, em 5 de dezembro de 2020, na Rússia, a vacinação contra a doença. No Brasil, o processo de vacinação foi iniciado em 17 de janeiro de 2021 (Baddini; Fernandes, 2021), após muitas polêmicas envolvendo a disseminação de notícias falsas sobre a vacina. Com o início da imunização, mas sem uma ação articulada do Ministério da Educação, sem uma organização das necessárias condições estruturais, sem um planejamento compartilhado para a retomada gradativa das aulas presenciais, cada estado brasileiro e cada município reorganizou sua retomada às atividades presenciais nas escolas, tendo que voltar atrás nessa decisão algumas vezes, quando do aumento do número de casos de internação e mortes.

Haverá imunização para todos? Será possível voltar às escolas? Considerando esse processo de transformações e mudanças, para onde poderia olhar o professor? Onde buscar elementos que o auxiliem? Seria uma questão de formação? De autoformação? Nessa reflexão, é importante considerar o que nos alerta Vaz (2012, p. 6): 
Muitas pesquisas que se referem à autoformação do professor são colocadas no sentido de o próprio professor buscar sua identidade profissional, de buscar a morte de antigas concepções para construir seu próprio ser, incentivando o professor a sentir-se responsável por sua formação, a procurar sozinho uma identidade para si. Tal posicionamento pode vir a ser uma ótima estratégia política para jogar sobre o professor exclusivamente as responsabilidades que as instituições de ensino e o próprio governo não deram conta de exercer $[. .$.$] .$

O alerta de Vaz (2012), de que a responsabilidade com a educação não é exclusiva do professor, faz-nos pensar que tanto a continuidade das atividades educacionais quanto o desejado retorno às atividades presenciais exigirão novas organizações dos espaços, dos ambientes, dos protocolos de segurança, do número de crianças por turma, das políticas de acesso a equipamentos de comunicação; bem como, quem sabe, na própria reorganização do tempo escolar, talvez como a que defende Neuscharank (2020, p. 18): “uma educação que é capturada pela cronologia, mas também a faz vazar, inventando em meio a pontualidades e horas delimitadas, intervalos para experimentar, 'perdas de tempo criadoras'".

É preciso refletir que o (a) professor (a) nunca será o (a) mesmo (a) sempre, ou seja, a cada formação, a cada encontro para estudo, a cada processo de mudança, ele (a) passa por processos de transformações, que ocorrem a partir do contato com seus pares, que pensam e são diferentes uns dos outros, e por discussões dos assuntos, dos estudos que realiza. Portanto, está em constante devir.

Ao discutir sobre como o professor inventa novas formas de ação, Vaz (2012, p. 3) destaca que:

Inventar modos de existir professor não significa abandonar tudo o que já sabe para encontrar novos conhecimentos mais adequados. Os próprios conceitos que já possuímos nos servem como possibilidades de encontros com outras experiências, não se trata de um abandono, mas de uma reterritorialização.

As possibilidades de transformação, reconstrução e reterritorialização, no entanto, podem ser relacionadas à abertura para o novo, o que Kohan (2011, p. 18) chama de infância, "[...] não como idade cronológica, mas como uma possibilidade afirmativa do pensar, como uma metáfora de gênese de um novo pensar." 
devir-professor brasileiro em tempos de pandemia

\section{sobre o devir-professor}

Kohan (2010, p. 12) nos lembra que “o aprender está antes de ensinar". Então, agora, nós professores precisamos buscar formas de (re) aprender, (re) existir, uma vez que o processo de formação não acaba, pois é contínuo, uma possibilidade de ser sempre outro.

A pandemia, que interrompeu nossas atividades, também ampliou o movimento de reflexão sobre o que é a escola e o que ela pode ser, bem como nos instigou a pensar sobre quem somos enquanto professores e o que queremos ser. À medida que investiga, busca, cria e pesquisa, o professor se forma e é formado, reconstrói-se. Os (as) professores (as) são sujeitos de múltiplas linguagens, que têm amplas possibilidades de interagir e dialogar com o mundo para além de seus processos de formação inicial ou continuada.

Segundo Deleuze e Guattari (2012, p. 67, grifos do autor),

Devir é, a partir das formas que se tem, do sujeito que se é, dos órgãos que se possui ou das funções que se preenche, extrair partículas, entre as quais instauramos relações de movimento e repouso, de velocidade e lentidão, as mais próximas daquilo que estamos em vias de devir, e através das quais devimos. É nesse sentido que o devir é o processo do desejo. Esse princípio de proximidade ou de aproximação é inteiramente particular e não reintroduz analogia alguma. Ele indica o mais rigorosamente possível uma zona de vizinhança ou de co-presença de uma partícula, o movimento que toma toda partícula quando entra nessa zona [...].

Sendo o devir um processo do desejo de um tornar-se, ainda não se é. Portanto, uma possibilidade de sermos o que ainda não somos, mas que temos potência para vir a ser, mesmo não tendo clareza do que podemos ser, nem direção única do que podemos ser. Então, será que nós professores (as) temos desejo de viver o processo do inacabado? Ou estamos satisfeitos com quem estamos sendo no momento presente? Será que estamos sentindo que temos experienciado toda a nossa potência de ser?

Citando Deleuze (1998), Kohan (2008) faz uma relação entre devir e temporalidade. Para ele, história e devir assumem lados diferentes. A história é entendida como o tempo chrónos, da sucessão de efeitos de uma experiência, totalizador e unificado, por isso se relaciona à macropolítica e à infância majoritária, que educa conforme um modelo totalizante, que ocorre nos estatutos, nos 
parâmetros, nas escolas. Ao devir, o autor relaciona o tempo do acontecimento, da duração, da intensidade, da experiência, um tempo aión, da criação, da descontinuidade, das linhas de fuga e das minorias, da infância minoritária.

O filósofo considera o quanto somos atravessados, simultaneamente, pelas duas temporalidades:

Somos habitantes dos dois espaços, das duas temporalidades, das duas infâncias. Uma e outra infância não são excludentes. As linhas se tocam, se cruzam, se enredam, se confundem. Não nos anima a condenação de uma e a mistificação da outra. Não somos juízes. Não se trata de combater uma e idealizar outra (Kohan, 2007, p. 95).

A perspectiva que Kohan (2007) nos apresenta sugere, então, um reconhecimento do que somos e do que podemos ser; não a partir de julgamentos ou condenação, nem em uma perspectiva de mistificação, mas de pensamento e ação se optarmos por uma abertura afirmativa para a novidade, para a infância. Algo muito valioso, especialmente diante de tantas incertezas desse período de pandemia.

Kohan (2008, p. 50) afirma que, a partir do sentido de devir, Deleuze criou o conceito de devir-criança, como a "interrupção da lógica histórica que se dá no tempo cronológico", de modo que o devir-criança não é tornar-se uma criança, mas encontrar-se no tempo do acontecimento, como uma expressão do ser humano, sem modelo e sem paradigma. “Devir-criança é assim, uma força que se extrai, da idade que se tem, do corpo que se é, os fluxos e as partículas que dão lugar a uma involução criadora” (Kohan, 2008, p. 50).

As reflexões sobre o "devir-criança" podem nos ajudar a pensar também o devir-professor. Assim, para Neuscharank (2020, p. 4), devir-criança é "ser menos adulta e mais criança”. A autora citada, ao usar a expressão "devir-criança”, está querendo construir a ideia de que mesmo pessoas adultas podem trazer algo do “estado" de uma criança, que pode, portanto, acompanhar-nos por uma vida.

Se “o devir-criança é uma forma de encontro que marca uma linha de fuga com relação à forma majoritária da subjetividade contemporânea, um novo espaço para poder sermos sempre de uma outra maneira, [...] sendo outros do que somos" (Kohan, 2008, p. 50), então também podemos ousar em um devir-professor como essa potência em movimento. 
devir-professor brasileiro em tempos de pandemia

Vaz (2012, p. 13) afirma que:

[...] pensar o processo formativo do professor implica em investir em possibilidades, ainda que provisórias, sendo elas devires, de construções de subjetividades a partir de experiências sociais, promovendo criações que potencializem outros sentidos além dos significados profissionais de 'ser professor', onde a docência possa se construir nas relações com o mundo, a partir das escolhas, acasos, agenciamentos e encontros.

Nenhum docente, ao concluir sua formação inicial, sabe com quais questões vai se defrontar na profissão, nem sabe com quais crianças trabalhará, quais desafios enfrentará no fazer diário nas salas de atividades, nem consegue realmente saber quais aprendizagens reais as crianças vão construir a partir do que será proposto. Por isso, é fundamental que entendamos o processo dinâmico da formação docente e o reconhecimento de que formar-se nessa visão do devir envolve dúvidas, resultados inesperados, mas que podem ser cheios de possibilidades de criação, de ultrapassar as incertezas e se descobrir e criar outras rotas.

Quando se fala no devir-professor, assim como no devir-criança, pode-se enfatizar as múltiplas linguagens. Muito embora ainda não sejam devidamente reconhecidas ou valorizadas, sempre será possível buscar oportunidades para viver suas dimensões criadoras, de viver a inteireza do seu ser em um momento presente, ao "educar para o sensível, para se pensar fora do pensamento único", como diz Neuscharank (2020, p. 3).

Nesse sentido, Arroyo (2012) sugere a necessidade da construção de uma nova ética, que possibilite atenção às condições de humanidade, dignidade e a criação de autoimagens mais positivas. Afirma, ainda, a necessidade de uma maior sensibilidade para as condições de trabalho e convivência dos professores entre si e com as crianças, e apresenta a arte como elemento que pode contribuir para uma visão mais cuidadosa do mundo e dos dramas sociais e humanos:

Há outro lado que mereceria ser trabalhado com centralidade na formação de professores e na formação de uma ética profissional: aumentar a consciência social no cinema, na literatura, nas artes e nas ciências sociais que exige ter eco nas pesquisas e análises pedagógicas. Uma consciência social contra os maus-tratos e as violências contra a infância, contra a mulher, contra os idosos... O mundo das artes, sobretudo tem-se feito eco desses dramas sociais, humanos, tem chamado a atenção sobre os dramas desses corpos- 
vidas tão maltratados. Tem tentado tirá-los do silenciamento, expôlos, entendê-los e apontar soluções (Arroyo, 2012, p. 47).

Também Leite e Ostetto (2012) afirmam a arte enquanto totalidade, conhecimento em si, e também defendem o encontro com a arte na formação do professor como uma maneira de propor sensibilidade, transgressão e construção. Para as pesquisadoras, somando-se à competência e ao compromisso, a sensibilidade pode abrir caminhos para o encantamento, possibilitando a recriação do cotidiano pessoal e profissional.

Referindo-se ao momento histórico do Brasil que antecede a pandemia, já nos alertava Abramowicz (2017, p. 16):

Estamos em um momento gravíssimo, onde quer que estejamos, temos que resistir! Resistir a quê? À tristeza que o momento nos impõe, à imobilidade que sentimos, à falta de perspectiva, à decepção quando todas as pautas pelas quais lutamos estão sendo destruídas em canetadas... resistir e forjar outros e novos encontros, pois as resistências estão por toda a parte e nem sempre sabemos de onde ela virá.

Esse contexto de pandemia da Covid-19 tem sido devastador. Temos visto muitas mortes, também muito embrutecimento, em uma batalha declarada em favor do mercado e do capital. Por outro lado, temos visto também resistência, criação de rotas de fuga. Durante a tristeza do isolamento, partilhamos incertezas, emoção, reinvenção, transformação, sensibilidade, resistência e buscas de resgate dos sentidos do humano.

\section{considerações finais}

O contexto mundial de pandemia, provocado pela Covid-19, afetou profundamente a forma de viver, trabalhar e se relacionar com o outro, especialmente devido ao isolamento social. Todos nos vimos diante de uma situação nova, difícil, perigosa e bastante desafiadora. Em nossos lares, tivemos que criar formas de continuar, apesar de todas as dores e perdas. No caso do professor, a continuidade de sua ação tem se dado especialmente pelo uso das novas tecnologias digitais, o que exigiu bastante disponibilidade. No entanto, é preciso estar atento para a defesa da escola pública, gratuita, universal e presencial, com condições dignas de funcionamento. 
devir-professor brasileiro em tempos de pandemia

Esse processo, no entanto, tem sido fortemente embarreirado pelas imensas desigualdades socioeconômicas às quais a maior parte da população brasileira é submetida pelas políticas neoliberais. No caso do Brasil, o governo federal mais tem se preocupado em negar a gravidade da pandemia e atacar a democracia e os professores do que em planejar e efetivar formas de acesso à educação no atual contexto. Ademais, exime-se de garantir os devidos protocolos de segurança sugeridos pelas agências de saúde para o gradativo retorno às atividades presenciais.

A vivência e a observação atenta da situação do Brasil no contexto da pandemia têm propiciado também muitas reflexões sobre a educação que temos e a educação que queremos, os professores que somos e os professores que queremos ser. Não tem sido fácil nos lançarmos ao novo, em algo que desafia, inquieta, incomoda, causa insegurança. Não é algo simples, justamente por ser desconhecido e exigir do sujeito outras habilidades, conhecimentos que até então não se tinha e que precisam ser construídos.

Ao olhar para as possibilidades de "devir-criança", enquanto desejo e abertura para o novo, sentimo-nos desafiadas a pensar em um "devir-professor", que se deixe atravessar por outra lógica, por outra temporalidade mais sensível e mais estética. Quem sabe o encontro com o outro de nós mesmos e com outros e, por que não, com a arte, com a infância, com o devir, possa nos ajudar a pensar, a resistir, a afetar, a movimentar e a transformar. Talvez esse seja um bom convite para todo (as) nós.

\section{referências}

Abramowicz, Anete. Educação infantil: implementar o exercício da infância. In: Abramowicz, Anete; Tebet, Gabriela Guarnieri de Campos (org.). Infância e pósestruturalismo. São Paulo: Porto de Ideias, 2017. p. 15-26.

Arroyo, Miguel G. Corpos precarizados que interrogam nossa ética profissional. In: Arroyo, Manuel G.; Silva, Maurício Roberto da (org.). Corpo infância: exercícios tensos de ser criança; por outras pedagogias dos corpos. Petrópolis: Vozes, 2012. p. 23-54.

Baddini, Bruna; Fernandes, Daniel. Primeira pessoa é vacinada contra Covid-19 no Brasil. CNN Brasil, São Paulo, 17 jan. 2021. Disponível em: https:/ / www.cnnbrasil.com.br/nacional/2021/01/17/primeira-pessoa-evacinada-contra-covid-19-no-brasil. Acesso em: 15 fev. 2021. 
Brasil confirma primeiro caso do novo coronavírus. Folha de S. Paulo, São Paulo, 25 fev. 2020. Disponível em: https://www1.folha.uol.com.br/equilibrioesaude/2020/02/brasilconfirma-primeiro-caso-do-novo-coronavirus.shtml. Acesso em: 15 fev. 2021.

Caponi, Sandra. Covid-19 no Brasil: entre o negacionismo e a razão neoliberal. Estudos Avançados, São Paulo, v. 34, n. 99, maio/ago. 2020. DOI: https://doi.org/10.1590/s0103-4014.2020.3499.013. 3499.013. Disponível em: https://www.scielo.br/pdf/ea/v34n99/1806-9592-ea-34-99-209.pdf. Acesso em: 15 fev. 2021.

Cnte. Escola pública laica, plural, gratuita, sem violência, desmilitarizada, democrática, de qualidade social, com profissionais valorizados/as, integral e para todos/as: eu acredito e vou à luta. Brasília, DF: CNTE, 2019. Disponível em: https://cnte.org.br/images/stories/2019/cnte--

20a_semana_nacional_em_defesa_da_educacao--livreto-final-web.pdf. Acesso em: 15 fev. 2021.

Deleuze, Gilles; Guattari, Félix. Mil platôs: capitalismo e esquizofrenia 2: volume 4. 2. ed. São Paulo: Editora 34, 2012.

Freitas, Luiz Carlos de. Ceará: tese mostra impacto da política educacional. Avaliação Educacional: Blog do Freitas, [S.l.], 21 jun. 2020. Disponível em: https:/ / avaliacaoeducacional.com/2020/06/21/ceara-tese-mostra-impacto-dapolitica-educacional/. Acesso em: 15 fev. 2021.

Frigotto, G. Prefácio. In: Bianchetti, Roberto G. Modelo neoliberal e políticas educacionais. 3. ed. São Paulo: Cortez, 1996. p. 9-15.

Gonçalves, Eduardo. Ricardo Salles fala em aproveitar a pandemia para 'ir passando a boiada". Veja, [S.l.], 23 maio 2020. Disponível em: https://veja.abril.com.br/politica/ricardo-salles-fala-em-aproveitar-a-pandemiapara-ir-passando-a-boiada/. Acesso em: 15 fev. 2021.

Kohan, Walter Omar. A devolver (o tempo d)a infância à escola. In: Abramowicz, Anete; TEBET, Gabriela Guarnieri de Campos (org.). Infância e pós-estruturalismo. São Paulo: Porto de Ideias, 2017. p. 11-14.

Kohan, Walter Omar. Infância e filosofia. In: Sarmento, Manuel; Gouvea, Maria Cristina Soares de (org.). Estudos da infância: educação e práticas sociais. Petrópolis: Vozes, 2008. p. 40-61.

Kohan, Walter Omar. Infância, estrangeiridade e ignorância: (novos) ensaios de filosofia e educação. Belo Horizonte: Autêntica, 2007.

Kohan, Walter Omar. Infância. Entre educação e filosofia. 2. ed. Belo Horizonte: Autêntica Editora, 2011.

Kohan, Walter Omar. Não há verdade sem alteridade. A propósito de "Devir- Criança da filosofia: infância da Educação". In: Kohan, Walter Omar. Devir criança da filosofia: infância da educação. Belo Horizonte: Autêntica Editora, 2010. p. 7-13.

Larrosa, Jorge. Esperando não se sabe o quê: sobre o ofício de professor. Tradução de Cristina Antunes. Belo Horizonte: Autêntica Editora, 2018.

Leite, Maria Isabel; Ostetto, Luciana Esmeralda. Formação de professores: o convite da arte. In: Ostetto, Luciana Esmeralda; Leite, Maria Isabel. Arte, infância e formação de professores: autoria e transgressão. Campinas: Papirus, 2012. cap. 1.

Morales, Raul. Dons, encargos, lugares, correções e tédio. In: Larrosa, Jorge. Esperando não se sabe o quê: sobre o ofício de professor. Belo Horizonte: Autêntica Editora, 2018. p. 162-170.

Moriyón, Félix García. A infância, um território fronteiriço. In: Kohan, Walter Omar. Devir criança da filosofia: infância da educação. Belo Horizonte: Autêntica Editora, 2010. p. 141-163. 
devir-professor brasileiro em tempos de pandemia

Neuscharank, Angélica. Notas de estudos sobre devir-criança, linguagem e tempo: "o tempo muda". ClimaCom: Devir Criança, Campinas, ano 7, n. 18, set. 2020. Disponível em: http://climacom.mudancasclimaticas.net.br/wpcontent/uploads/2020/09/ ARTIGO-9-Notas-de-estudos-sobre-devir-crian--alinguagem-e-tempo.pdf. Acesso em: 15 fev. 2021.

Shiroma, O. E.; Moraes, M. C.; Evangelista, O. Política educacional. 4. ed. Rio de Janeiro: Lamparina, 2011.

Trindade, Marcos Aurélio. O conceito de "ser mais" em Paulo Freire e a relação professoraluno. Revista Comfilotec, ano 4, v. 7, 2018. Disponível em: https://www.fapcom.edu.br/wp-content/uploads/2018/05/Marcos-comfilotecartigo-ensaios-1.pdf. Acesso em: 15 fev. 2021.

Vaz, Tamiris. Docência em deriva: atravessamentos de um 'devir professor'. In: Seminário ANPED SUL, 9., 2012, Caxias do Sul. Anais eletrônicos [...]. Caxias do Sul: ANPED, 2012.

em: http://www.ucs.br/etc/conferencias/index.php/anpedsul/9anpedsul/paper/vi ew/1243/790. Acesso em: 15 fev. 2021.

Vidale, Giulia. Novas variantes já foram detectadas em 10 estados e Distrito Federal. Veja, São Paulo, 20 fev. 2021. Disponível em: https://veja.abril.com.br/saude/novasvariantes-ja-foram-detectadas-em-10-estados-e-distrito-federal/. Acesso em: 20 fev. 2021.

recebido em: 20.02.2021

aprovado em: 12.03.2021 